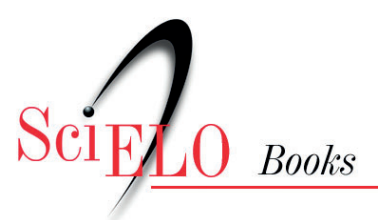

\title{
4. Políticas públicas para a produção de materiais didáticos para educação de jovens e adultos no Brasil entre 1995 e 2017 avanços, contradições e recuos
}

\author{
Paulo Eduardo Dias de Mello
}

\section{SciELO Books / SciELO Livros / SciELO Libros}

MELLO, P.E.D. Políticas públicas para a produção de materiais didáticos para educação de jovens e adultos no Brasil entre 1995 e 2017: avanços, contradições e recuos. In: PAIVA, J., comp. Aprendizados ao longo da vida: sujeitos, políticas e processos educativos [online]. Rio de Janeiro: EDUERJ, 2019, pp. 79-96. Pesquisa em educação/Educação ao longo da vida series. ISBN: 978-65990364-9-1. https://doi.org/10.7476/9786599036491.0005.

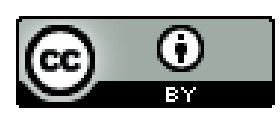

All the contents of this work, except where otherwise noted, is licensed under a Creative Commons Attribution 4.0 International license.

Todo o conteúdo deste trabalho, exceto quando houver ressalva, é publicado sob a licença Creative Commons Atribição $\underline{4.0}$.

Todo el contenido de esta obra, excepto donde se indique lo contrario, está bajo licencia de la licencia Creative Commons $\underline{\text { Reconocimento } 4.0 .}$. 
4

\section{Políticas públicas para a produção de materiais didáticos para educa- ção de jovens e adultos no Brasil entre 1995 e 2017: avanços, contra- dições e recuos}

Paulo Eduardo Dias de Mello

\section{Introdução}

No Brasil, a oferta de oportunidades de escolarização para jovens e adultos que não concluíram a educação básica representa o resgate de uma dívida histórica. Segundo dados estatísticos atuais, cerca de 65 milhóes de brasileiros possuem menos de oito anos de estudos, e cerca de 12 milhóes são analfabetos. ${ }^{1}$ Desde a Lei de Diretrizes e Bases da Educação Nacional (LDBEN), de 1996, a educação de jovens e adultos (EJA), constituída como uma modalidade específica da educação básica, tem como objetivo assegurar uma oferta educacional qualificada para essa ampla parcela da população. Um dos elementos de qualificação dessa

1. Instituto Brasileiro de Geografia e Estatística (IBGE). Pesquisa Nacional por Amostra de Domicílios (PNAD) 2011. Disponível em http://www.ibge.gov.br/home/presidencia/noticias/ imprensa/ppts/00000010135709212012572220530659.pdf. Acesso em 2 nov. 2013. 
oferta são os materiais didáticos (em especial os livros didáticos) oferecidos aos alunos, que necessitam ser adequados ao perfil e às necessidades dos estudantes da EJA, e que dialogue e viabilize as potencialidades de construção de currículos em ação nos contextos escolares e não escolares.

De fato, o tema dos materiais didáticos, seu lugar nas políticas da Uniâo ${ }^{2}$ para a EJA, e suas relaçóes com as propostas e os métodos de educação de jovens e adultos no Brasil têm sido historicamente objeto de discussóes. ${ }^{3}$ Segundo Fávero (2007), pelo menos desde o início dos anos 1960, momento de eclosão de vários movimentos e engendramento de propostas de educação popular no país, a temática dos materiais didáticos passou a ocupar posição de destaque na pauta de debates sobre o tema. Mais recentemente, na década de 1990, vários documentos produzidos pelos Fóruns de $\mathrm{EJA}^{4}$ e nos encontros nacionais de entidades ligadas à EJA destacaram a produção de materiais didáticos como elemento importante da viabilização de propostas e práticas educativas na EJA.

Neste trabalho retomamos o período recente da história da educação brasileira, identificando quais foram as atuaçóes da União na formulação e execução de políticas para EJA, destacando a questão dos materiais didáticos. Exploramos, inicialmente, quais foram as linhas mestras dessas políticas implantadas durante os governos

2. No Brasil, a União representa o governo federal, cuja atribuição é desenvolver políticas públicas de âmbito nacional.

3. Nas pesquisas sobre EJA, o tema dos materiais didáticos tem como referência os trabalhos de Fávero (1984; 2006; 2007; 2010 e s. d.), Beisiegel (1984 e 2004) e Paiva (1984 e 2007), que abordam os materiais didáticos produzidos no âmbito de programas e açóes desenvolvidos desde a década de 1940.

4. O movimento dos Fóruns de Educação de Jovens e Adultos surgiu em meados da década de 1990, tendo como pauta atuar no processo de construção de políticas públicas de EJA, que assegurassem direitos na área da educação. $\mathrm{O}$ movimento possui um Portal no seguinte endereço: http://www.forumeja.org.br/ 
dos presidentes Fernando Henrique Cardoso (1995 a 2002) e Luís Inácio Lula da Silva (2003 a 2010), e analisamos suas relaçóes com a sociedade civil e o mercado editorial, na produção de materiais didáticos para a EJA. Por fim, indicamos alguns dos impasses e desafios atuais que se impóem para a questáo dos materiais didáticos para a EJA, após sua inserção no Programa Nacional do Livro Didático (PNLD).

\section{Produção didática para EJA nos anos 1990: entre certifica- çáo e produçóes coletivas}

No campo da EJA, o período histórico que se estende entre 1990 até 2002 - que antecede e se prolonga até o final do segundo mandato do presidente Fernando Henrique Cardoso (FHC) - foi tensionado pelos embates travados em torno dos marcos legais da EJA e das lutas pela implantação de políticas concretas que assegurassem as conquistas obtidas. $\mathrm{Na}$ expressão de Haddad (2007), a década foi marcada pelos "embates entre as conquistas formais de direitos e a negação real pelas políticas". Assim, por um lado, desenvolvem-se os enfrentamentos promovidos por segmentos que buscavam promover avanços no arcabouço legal que se formulava no país, a partir: da Constituição de 1988; do Plano Decenal de Educaçáo para Todos de 1993; da Lei de Diretrizes e Bases da Educação Nacional de 1996; da Lei n. 9.424/96 que cria o Fundo de Manutenção e Desenvolvimento do Ensino Fundamental e de Valorização do Magistério (FUNDEF); das discussões sobre Diretrizes Curriculares Nacionais; e do Plano Nacional de Educação de 2001. Por outro lado, desenvolveram-se as lutas pela efetiva implantação das normas legais pelos agentes públicos, por meio de políticas que assegurassem os avanços obtidos.

Entre 1997 e 2002, durante o governo FHC, o Fundo Nacional de Desenvolvimento da Educação (FNDE), uma autarquia 
federal ligada ao Ministério da Educação, passou a responder pelo apoio financeiro da Uniáo aos Estados e Municípios para programas de ensino fundamental de jovens e adultos. As iniciativas da União para a alfabetização e capacitação profissional de jovens e adultos passaram a ser coordenadas por setores náo educacionais do governo federal, caracterizando-se por intervençóes focalizadas ou de caráter compensatório, destinadas a atender prioritariamente as regióes mais pobres do país, destacando-se o Conselho da Comunidade Solidária, no caso do Programa Alfabetização Solidária (PAS); o Ministério do Trabalho e Emprego, como aconteceu com o Plano Nacional de Qualificação Profissional (PLANFOR); e o Ministério do Desenvolvimento Agrário, no caso do Programa Nacional de Educação na Reforma Agrária (PRONERA) (Graciano e Di Pierro, 2003).

Nesse ínterim, a Coordenação de Educação de Jovens e Adultos (COEJA), no Ministério da Educação, desenvolveu uma série de iniciativas voltadas à reformulação de referenciais curriculares, disseminação de materiais didáticos e implantação de um programa de formaçáo de educadores das redes de escolas estaduais e municipais. Assim, após a elaboração e aprovação das novas Diretrizes Curriculares Nacionais (DCN), em 2000, foram formulados novos Parâmetros Curriculares Nacionais para a EJA (PCN/EJA) e um novo modelo de certificação de estudos: o Exame Nacional de Certificaçáo de Competências de Jovens e Adultos (ENCCEJA).

Esses instrumentos normativos articulados demonstravam a intenção da Uniáo de fornecer elementos para a reorganizaçáo do quadro da EJA no país, subsidiando e reorientando as políticas dos demais agentes públicos ou privados que atuavam no setor, tais como secretarias estaduais e municipais de educação, sindicatos, movimentos sociais, organizaçóes náo governamentais, entre outros agentes sociais. Esse processo envolveu uma série de situa- 
çóes contraditórias e resultou em diferentes embates envolvendo agentes sociais ligados à EJA, que se articulavam especialmente em torno dos Fóruns de EJA.

De fato, é no movimento das reformas educativas do governo FHC que as articulações entre currículo, produção didática e, posteriormente, exames passam a ter destaque como instrumentos combinados de uma política educacional destinada a conformar uma proposta para a EJA. Na realidade, esse processo de discussão inicia-se em meados dos anos 1990, com a elaboração da proposta curricular para o primeiro segmento da EJA e a produção da coleção didática Viver Aprender. A iniciativa da elaboração curricular coube à Ação Educativa, organização náo governamental que atua na área de educação e juventude. Em 1996, o MEC coeditou e distribuiu essa proposta curricular, após manifestar intenção à Comissão Nacional de Educação de Jovens e Adultos (CNAEJA). Alguns anos depois, em 2000, deu continuidade a essa iniciativa e organizou a Proposta Curricular para o Segundo Segmento do Ensino Fundamental da Educação de Jovens e Adultos - EJA (correspondente à etapa de $5^{\mathrm{a}}$ a $8^{\mathrm{a}}$ séries do ensino fundamental), mas dela não decorreu nenhuma proposta oficial para produção de material didático. A elaboração de material didático ocorreria apenas em 2002, mas já como parte do processo de formulaçáo do Exame Nacional de Certificação de Competências da EJA, o ENCCEJA. Dessa forma, ao longo do governo FHC, a questáo do material didático para EJA passou de uma conformaçáo orientada por um currículo prescrito para uma nova forma de configuraçáo definida pelo currículo avaliado; ou seja, os exames de certificação.

Ao mesmo tempo em que desenvolvia esta política centralizada de currículo e avaliação, em 2001 — mas com tempo previsto de execução até 2003 —, foi lançado o Programa de Apoio a Estados e Municípios para a Educação Fundamental de Jovens e Adultos, 
denominado Programa Recomeço - Supletivo de Qualidade, integrado ao Projeto Alvorada. O governo preconizava articular as açóes da EJA a um conjunto de programas sociais, de infraestrutura e desenvolvimento que, em tese, estariam voltados para a redução das desigualdades regionais e melhoria das condiçóes de vida nas localidades mais carentes do Brasil. $\mathrm{O}$ objetivo do Programa Recomeço era apoiar, com recursos financeiros, estados das regióes Norte e Nordeste e municípios de microrregióes com baixo Índice de Desenvolvimento Humano (IDH). Era também prover ensino fundamental a jovens e adultos, assegurando a continuidade de estudos aos egressos do Programa Alfabetização Solidária. Entre suas açóes, o PAS previa a aquisição de livro didático ou módulo e/ou impressão de material didático adequado à educação de jovens e adultos do ensino fundamental, 1. e 2 . $^{\circ}$ segmentos; a aquisição e reprodução de materiais didáticos e pedagógicos.

Portanto, as atuações da Uniâo, no período do governo FHC, no âmbito do MEC, relacionadas à produção didática para a EJA, foram marcadas pelo Programa Recomeço, criado para complementar recursos destinados à EJA, e que financiou a produção de materiais didáticos pelas secretarias municipais e estaduais; e pelo PAS, que adotou a coleção Viver Aprender, e desenvolveu, junto a seus parceiros, materiais para a campanha de alfabetização. A produção didática passa a ser ferramenta de controle da oferta da EJA, vinculando-se à questáo do currículo e articulando-se aos exames de certificação por meio do ENCCEJA. A política do governo FHC oscila entre a descentralização de recursos para a produção didática localizada, e a definição de instrumentos normativos - currículos e exames - que definem formas e conteúdos para essa produção.

Por outro lado, além dos materiais que resultam das açóes da União, vários outros surgem como resultado de iniciativas de governos municipais ligados à gestão de partidos considerados 
progressistas, como o Partido dos Trabalhadores (PT). A experiência do PT na prefeitura de São Paulo em 1990, com a presença de Paulo Freire à frente da Secretaria de Educação, foi fonte de inspiração para o resgate de experiências anteriores à ditadura militar, nas quais a participação da sociedade civil era fundamental para promover a inclusáo educacional das parcelas pobres da população.

Foi nesse contexto, por exemplo, que surgiu o Movimento de Alfabetização (MOVA). O MOVA espalhou-se por todo o país, em governos municipais e estaduais de diversos partidos, mas principalmente nas gestóes do Partido dos Trabalhadores. De acordo com Haddad (2007), o modelo implementado, ao envolver entidades e movimentos sociais, fortaleceu no âmbito da sociedade civil a demanda por EJA e por experiências educacionais, as quais estimulavam a produção de materiais didáticos coletivamente por professores e estudantes.

Algumas prefeituras também protagonizaram, por meio de suas equipes pedagógicas, a produção de materiais didáticos significativos. Em Porto Alegre, foram editados pelo Sistema de Educação de Jovens e Adultos (SEJA) os livros Palavras de trabalhador, produtos da experiência educativa realizada com jovens e adultos trabalhadores, e o conceito de totalidades do conhecimento nos livros. Em Goiás, como resultado de uma parceria entre o MEB, a secretaria municipal de Goiânia e o Instituto Brasil Central da Diocese de Goiânia, foram elaborados alguns materiais didáticos, entre eles a coletânea de textos Nossa Vida Lida e Escrita (1996); a coletânea de textos e atividades de leitura e escrita De um Tudo (1998); e a coletânea desenvolvida por professores e estudantes Um Passo na Construçáo da Nossa Pasta do Projeto AJA (1996 e 2000). ${ }^{5}$ Assim, durante a década de 1990 , vários materiais foram

5. As informaçôes sobre os materiais produzidos em Goiás foram obtidas no Museu Virtual organizado pela equipe da Faculdade de Educação no endereço: http://www.fe.ufg.br/museu. 
produzidos no âmbito das experiências educativas, patrocinadas por prefeituras progressistas ou desenvolvidas por ONGs, ligadas aos princípios dos movimentos de educação e cultura popular.

Além dessas produçóes, instituiçóes ligadas ao movimento dos trabalhadores - como a Central Única dos Trabalhadores (CUT) — em parceria inicial com a PUC/SP e depois com a Universidade Federal do Rio de Janeiro (UFRJ), a Unitraba$1 h o^{6}$ e o Departamento Intersindical de Estatística e Estudos Socioeconômicos (DIEESE), produziram materiais didáticos significativos no interior dos Programas Integrar e Integração. O Movimento dos Trabalhadores Rurais Sem-Terra (MST) também desenvolveu materiais didáticos para serem utilizados nos acampamentos e assentamentos.

A partir do final dos anos 1990, o segmento das editoras comerciais também viveu um cenário de expansão propiciado pelo processo de consolidação dos cursos de EJA, especialmente quando, em 1998, o Fundo Nacional de Desenvolvimento da Educação (FNDE) passou a apoiar estados e municípios na produção e aquisição de materiais por meio do Programa Recomeço. A facilidade de uso dos recursos promoveu a presença de editoras com produção didática destinada à EJA em praticamente todas as regióes do país, com exceção do Centro-Oeste. Mesmo assim verificou-se uma concentração do mercado, com 36\% das edito-

6. Fundado em 29 out. 1998, o Núcleo/Incubadora Unitrabalho (UEM) realiza pesquisa, extensão e estudos sobre o mundo do trabalho e os movimentos sociais. Formado por docentes, pesquisadores, técnicos e discentes de diversas áreas profissionais, produz e difunde conhecimento, apoiando iniciativas locais para a geração de renda, concretizando políticas de trabalho e sociais na perspectiva dos direitos e defesa da cidadania do trabalhador. Seu objetivo é que a Universidade e os trabalhadores interajam para o desenvolvimento de projetos e açóes que subsidiem suas lutas por melhores condiçóes de vida, trabalho e renda. Disponível em: http://www.unitrabalho.uem. br/sobre-34\#1 . Acesso em 2 jun. 2018.

7. Os materiais didáticos da CUT, do SEJA de Porto Alegre e do MST foram analisados por Fávero (2007). 
ras sediadas em São Paulo, 21\% em Curitiba, e 15\% em Fortaleza. Além disso, a produção destinada à EJA revelou estratégias comerciais e dispositivos editoriais que demonstravam uma produção de baixa qualidade editorial, fosse do ponto de vista da materialidade ou do conteúdo escolar. ${ }^{8}$

\section{Produçáo didática para EJA no governo Lula: avanços e contradiçóes}

A partir de 2003, no governo de Luís Inácio Lula da Silva, as reformas educativas efetuadas na gestáo anterior passaram a ser objeto de reconsiderações e revisóes. O próprio MEC sofreu várias reformulaçôes com a reorganização de sua estrutura. Programas, projetos e açôes do MEC foram, aos poucos, reorientados. Para enfrentar a questáo do analfabetismo, por exemplo, foi criado o Programa Brasil Alfabetizado (PBA) em 2003. A EJA, nesse processo de reformulação da política educacional, passou a ser responsabilidade da Secretaria de Educação Continuada, Alfabetização e Diversidade (SECAD), criada em 2004. O Programa Recomeço foi rebatizado de Fazendo Escola, sofreu algumas alteraçóes e foi progressivamente estendido a todas as regiôes do país, com valores per capita diferenciados em uma escala proporcional ao déficit educativo das localidades.

No novo contexto dado pela criação da SECAD, a atuação da União em relação à produção didática voltada à EJA dividiu-se entre a elaboraçáo pelo MEC de uma proposta de material didático de caráter interdisciplinar e flexível, a coleção Cadernos de

\footnotetext{
8. Veja-se a respeito Mello (2010), quando analiso detalhadamente a produção didática de EJA das editoras comerciais indicando estratégias editoriais que comprometem a qualidade da produção. Disponível em: http://www.teses.usp.br/teses/disponiveis/48/48134/tde-26012011-142038/ pt-br.php. Acesso em 7 jun.2018.
} 
$E J A$ (2007), que foi articulada à formação do professor por meio da coleção Trabalhando com EJA (2006); a produção de novos materiais didáticos voltados à promoção da leitura de jovens e adultos recém-alfabetizados, como o Almanaque Aluá n. 2 e a coleção Literatura para Todos (2006); além da manutenção da política de transferência de recursos financeiros aos entes federados por meio de programas como o Fazendo Escola e o PBA, e de materiais vinculados aos exames de certificação, o ENCCEJA.

A criação do Programa Nacional do Livro Didático para a Alfabetização de Jovens e Adultos (PNLA), em 2007 (Resolução n. 18, de 24 de abril de 2007), no âmbito do PBA, representou um momento de inflexão da política de materiais didáticos implementada até então. A EJA foi incluída no Programa Nacional do Livro Didático (PNLD), ainda que, naquele momento, atendendo apenas à etapa de alfabetização. Com o fim do Fazendo Escola, a inclusão da EJA no recém-reformulado Fundo de Manutenção e Desenvolvimento da Educação Básica e de Valorização dos Profissionais da Educação (FUNDEB), ' a política da SECAD desloca-se da transferência de recursos para entidades, para o investimento em programas que estimulam a produção centralizada de materiais didáticos, com foco no livro, passando a beneficiar o mercado editorial.

Mantendo essa tendência, as edições do PNLA de 2009 e 2010 ampliaram o universo de alunos atendidos, passando a incorporar, além dos alfabetizandos inscritos no PBA, as turmas regulares de alfabetização na educação de jovens e adultos das

9. O Fundo de Manutenção e Desenvolvimento da Educação Básica e de Valorização dos Profissionais da Educação (Fundeb) foi criado pela Emenda Constitucional n. 53/2006 e regulamentado pela Lei n. 11.494/2007 e pelo Decreto n. 6.253/2007, em substituição ao Fundo de Manutenção e Desenvolvimento do Ensino Fundamental e de Valorização do Magistério (Fundef), que vigorou de 1998 a 2006. Disponível em http://portal.mec.gov.br/fundeb-sp-1090794249. Acesso em 7 jun. 2018. 
redes públicas de ensino. Por fim, ainda em 2009, o PNLA foi extinto e incorporado a um novo programa, mais amplo: o Programa Nacional do Livro Didático para a Educação de Jovens e Adultos (PNLD EJA, 2011). Criado pela Resolução n. 51, de 16 de setembro de 2009, o PNLD EJA passou a distribuir obras e coleçôes didáticas para todas as escolas públicas com turmas de EJA e para as turmas de alfabetizaçáo das entidades parceiras do Programa Brasil Alfabetizado. Em sua primeira edição, em 2011, o Programa atendeu cerca de quatro milhóes de estudantes e professores, tendo distribuído aproximadamente 17 milhóes de livros.

Tabela 1: Resultado do processo de avaliação do PNLD EJA 2011 ( ${ }^{\circ}$ de obras)

\begin{tabular}{|c|c|c|c|}
\hline Etapa da EJA & Avaliadas & Aprovadas & Reprovadas \\
\hline Alfabetização & 27 & 14 & 13 \\
\hline Anos iniciais EF & 14 & 03 & 11 \\
\hline Anos finais EF & 10 & 02 & 08 \\
\hline $\begin{array}{c}\text { Regionais de História e } \\
\text { Geografia }\end{array}$ & 14 & 02 & 12 \\
\hline Total & 65 & 21 & 44 \\
\hline
\end{tabular}

Fonte: Tabela elaborada pelo autor a partir de dados do FNDE

Os resultados do processo de avaliação do PNLD EJA 2011 indicam que apenas 32\% das obras avaliadas foram aprovadas. Mas o fato de já ter havido um processo de avaliação por conta do anterior PNLA mascara o resultado. Muitas obras aprovadas no PNLD EJA já haviam sido aprovadas no PNLA. Assim, se considerarmos a avaliação dos livros do anos iniciais e finais do EF e regionais que nunca haviam sido submetidos à avaliação, verificamos que o índice de aprovaçáo foi de apenas $21 \%$ das obras. O elevado índice de reprovação revela, portanto, a baixa qualidade pedagógica do material destinado à EJA produzido no país pelo mercado editorial. 
Outros aspectos ainda chamam atenção no resultado. $\mathrm{O}$ primeiro revela a dinâmica de concentração do mercado editorial. Das onze editoras que tiveram suas coleçóes aprovadas, apenas três editoras, todas situadas no estado de São Paulo, foram responsáveis por $57 \%$ das obras aprovadas: a Ática (quatro coleçôes); a FTD (cinco coleções); e a Global (três coleções). Outro aspecto é que duas das três coleçôes aprovadas no PNLD EJA pela editora Global já haviam sido produzidas e distribuídas pelo próprio MEC no governo FHC. Com o fim do governo FHC, a Ação Educativa, que detinha os direitos autorais da coleção, passou a publicá-la pela editora Global. Com isso, o número de obras inéditas aprovadas poderia ser reduzido a escassos $10 \%$ das coleçóes avaliadas.

Outro elemento central da política de materiais didáticos no governo Lula foi a produção de material literário destinado ao público da EJA. Para tanto, foi criado em 2005, o Concurso Literatura para Todos, com o objetivo de estimular a produção literária destinada a jovens, adultos e idosos em processo de alfabetização. Segundo Maciel (2007, p. 538) a produção do material literário da coleção procurou atender especificidades da EJA, ou o chamado neoleitor, desde seu projeto editorial:

A coleção destaca-se por seu projeto gráfico. Foi avaliado que o tamanho dos textos literários em circulação, a complexidade da forma, a falta de intimidade com autores e obras deixam à margem excelentes oportunidades de aproximar os neoleitores dos textos literários. [...] No projeto gráfico considerou-se também que os livros precisariam ser ao mesmo tempo atraentes e práticos e para isso foram selecionados diversos estilos de ilustraçóes que dialogam com o texto e o universo do neoleitor. A coleção tem um formato e uma mancha gráfica que pretende favorecer a aproximaçáo do neoleitor com o texto e tornar os livros simples e bonitos. 
Mas, a partir de 2009, seguindo uma nova diretriz da política de materiais didáticos, pautada pela inclusão da EJA em editais gerais destinados à educação básica, a SECAD promoveu a chamada de obras literárias destinadas a todos os segmentos da EJA no edital do Programa Nacional Biblioteca da Escola (PNBE). O desafio que o PNBE trouxe foi como identificar obras literárias que atendessem o público da EJA. Isso rompia com a lógica do Concurso Literatura para $\operatorname{Todos}^{10}$ que previa a elaboraçáo de textos exclusivamente pensados para o público da EJA. De certo modo, a inserção da EJA no PNBE questionou a necessidade de produção ou mesmo a existência de materiais literários em formatos específicos para o público da EJA, indicando disjunçóes entre iniciativas do próprio MEC.

Para equilibrar as estratégias de inserção da EJA nas açóes da educação básica, a SECAD tomou algumas iniciativas de fomento à produção de materiais didáticos que não privilegiassem apenas grupos organizados de produtores ligados ao mercado editorial. Ainda no final de 2008, foram lançadas duas resoluçóes voltadas à produção ou ao fomento à produção de materiais didáticos diversos destinados à EJA. A Resolução n. 51 visava ao fomento à produção de material pedagógico-formativo e de apoio didático à EJA, com ênfase na economia solidária. Por sua vez, a Resoluçáo n. 44 estimulava projetos da sociedade civil que deveriam contemplar a promoçáo de acesso à leitura e à formação de leitores e mediadores de leitura; a produção e distribuiçâo de tecnologias educacionais de fomento à leitura; e a pesquisa e avaliação sobre leitura.

Em suma, podemos dizer que a Uniáo, durante o governo Lula, por meio da SECAD, manteve uma política de materiais didáticos para a EJA que oscilou entre o estímulo dirigido à pro-

10. O Concurso chegou a ter três ediçôes premiadas, mas somente a primeira teve as obras publicadas e distribuídas. 
dução de materiais didáticos diversos, com perfil pedagógico e editorial definido, que deveriam favorecer os setores da sociedade civil; e iniciativas de captação ou chamada pública de materiais didáticos, por meio de editais conjuntos com a Secretaria de Educação Básica (SEB) que, de certo modo, privilegiavam segmentos organizados do meio editorial com maior capacidade de atender os rígidos critérios formais e técnicos de avaliação dos programas do livro, em especial o PNLD. Por outro lado, essas iniciativas de distribuição de materiais careceram de acompanhamento e avaliação sobre seus impactos nas práticas educativas da EJA e na produçáo didática para a modalidade, em particular do mercado de livros didáticos no Brasil.

\section{Consideraçóes finais}

Uma análise sobre as políticas públicas para produção didática destinada à EJA, nas últimas duas décadas, revela tensóes, aproximaçóes e contradiçóes entre atuaçóes do Estado, dos segmentos da sociedade civil e agentes do mercado provenientes da indústria cultural. Trata-se de uma trajetória marcada pela tensão entre continuidade e descontinuidade de programas educacionais e por disputas entre concepçôes distintas sobre que papel devem representar os materiais didáticos nos processos pedagógicos da EJA. Essa trajetória é, portanto, intrinsecamente vinculada às contradiçóes do contexto histórico. Também é ligada aos embates em torno dos projetos e propostas políticas educativas para a EJA, expressando o antagonismo entre propostas que insistem na certificação e promoção acelerada e aligeirada de formação para conclusão de estudos, e aquelas que projetam formas de educação continuada numa perspectiva política de emancipação social vinculadas às experiências de educação popular. 
A tentativa de formulação de uma política específica para produção de materiais didáticos para a EJA foi aprofundada no governo Lula, não mais centrada apenas na articulação entre currículo prescrito, exames padronizados e materiais didáticos preparatórios, como no governo de seu antecessor Fernando Henrique Cardoso. Esse aprofundamento indica uma pluralização de iniciativas, envolvendo a diversidade de sujeitos produtores, e o estímulo à produçáo de uma multiplicidade de materiais nos mais diferentes suportes, linguagens e conteúdos.

Todavia, trata-se de uma proposta contraditória e incompleta. Falta ao Brasil uma política articulada de fomento da produção e/ou aquisição de materiais didáticos para a EJA que contemple a sua diversidade de iniciativas, que se baseie em critérios de avaliação comuns e específicos para os materiais produzidos, seja no âmbito dos programas oficiais ou das iniciativas apoiadas pelo Estado. Além disso, as próprias iniciativas oficiais se multiplicam internamente na estrutura da União e no âmbito de outras esferas, sobrepondo açóes de secretarias e autarquias, algumas convergentes e outras que indicam divergências teóricas e práticas entre os projetos de EJA.

Seria fundamental que o Estado brasileiro assumisse o papel de articular suas açóes nos marcos de uma política coerente, de forma a assegurar a pluralidade de sujeitos produtores, evitando a homogeneização da produção didática e a concentração dessa produção nas mãos das grandes editoras e, ao mesmo tempo, garantindo padróes básicos de qualidade para as produçóes de sujeitos locais. Nesse sentido, mais que proporcionar a produção de um mosaico disperso de materiais, seria preciso pensar a composição de acervos didáticos diversos e coerentes com uma proposta de EJA plural e democrática.

Assim, não basta ao Estado brasileiro, em especial, à Uniáo, atuar como um mero distribuidor de materiais avaliados e adquiridos 
dos grandes produtores do mercado editorial, ou apenas como um distribuidor de recursos financeiros a entidades da sociedade civil que se propóem a produzir seus próprios materiais didáticos. É preciso, simultaneamente, acompanhar os resultados alcançados com a aplicação dos recursos transferidos por meio de programas de descentralização. Além disso, é necessário estar atento aos efeitos que uma produção didática em massa pode trazer para a EJA, identificando quais são os usos escolares dos materiais entregues pelos programas e quais as possibilidades de reinvenção desses recursos que existem nos espaços escolares.

\section{Referências}

BEISIEGEL, Celso de Ruy. "Ensino público e educação popular". In PAIVA, Vanilda Pereira (org.). Perspectivas e dilemas da educação popular. Rio de Janeiro: Graal, 1984.

- Estado e educação popular: um estudo sobre a educação de adultos. Brasília: Liber Livro, 2004.

BRASIL. "Lei n. 9.394, de 20 de dezembro de 1996". Estabelece as diretrizes e bases da educação nacional. Brasília, Distrito Federal, 1996.

- Proposta Curricular para o Segundo Segmento do Ensino Fundamental da Educação de Jovens e Adultos - EJA. Brasília: MEC, 2002.

DI PIERRO Maria Clara, GRACIANO, Mariângela. Educação de Jovens e Adultos no Brasil: informe apresentado à Oficina Regional da UNESCO para América Latina e Caribe. São Paulo: Ação Educativa, 2003.

FÁVERO, Osmar. "Referências sobre materiais didáticos para a educação popular”. In PAIVA, Vanilda Pereira (org.). Perspectivas e dilemas da educação popular. Rio de Janeiro: Graal, 1984.

FÁVERO, Osmar. Uma pedagogia da participação popular: análise da prática educativa do MEB - Movimento de Educação de Base (1961/1966). Campinas: Autores Associados, 2006. (Coleção Educação Contemporânea).

e RIVERO, José. Educação de Jovens e adultos na América Latina: direito e desafio de todos. UNESCO: Fundaçáo Santillana, s. d. 
HADDAD, Sérgio. "A educação continuada e as políticas públicas no Brasil". In REVEJ@ - Revista de Educação de Jovens e Adultos, v. 1, n. 0, pp. 27-38, ago. 2007.

MACIEL, Ira Maria. "Coleção Literatura Para Todos. MEC. 2006”. Resenha publicada na Rev. Bras. Educ, v. 12, n. 36, Rio de Janeiro, set./dez. 2007. Disponível em: http://www.scielo.br/scielo.php?script=sci_arttext\&pid=S1 41324782007000300014\&lng=en\&nrm=iso. Acesso em 7 jun. 2018.

MELLO, Paulo Eduardo Dias de. Materiais didáticos para a Educação de Jovens e Adultos: história, formas e conteúdos (tese). Universidade de São Paulo, São Paulo, 2010.

PAIVA, Vanilda Pereira. Educação popular e educação de adultos. 2 ed. Sáo Paulo: Loyola, 1983.

\section{Materiais Didáticos}

AÇÃO EDUCATIVA. Coleção Viver Aprender. São Paulo: Global, 2013. Disponível em: http://www.viveraprender.org.br/colecao/. Acesso em 7 jun. 2018.

BRASIL. Cadernos de EJA. Brasília: MEC, 2006. Disponível em: http://portal. mec.gov.br/observatorio-da-educacao/194-secretarias-112877938/secad-educacao-continuada-223369541/13536-materiais-didaticos . Acesso em 7 jun. 2018.

. Trabalhando com EJA. Brasília: MEC, 2006. Disponível em: http:// portal.mec.gov.br/observatorio-da-educacao/194-secretarias-112877938/ secad-educacao-continuada-223369541/13536-materiais-didaticos. Acesso em 7 jun. 2018.

. Coleção Literatura para Todos. Brasília: MEC, 2006. Disponível em: http://www.dominiopublico.gov.br. Acesso em 7 jun. 2018.

GOIÂNIA, Secretaria Municipal de Educação. Nossa Vida Lida e Escrita. Goiânia, 1996.

. Secretaria Municipal de Educação. Um Passo na Construção da Nossa Pasta do Projeto AJA. Goiânia, 2000.

MOVIMENTO DE EDUCAÇÃO DE BASE. De um Tudo. Goiânia: MEB, 1998. 
96 Aprendizados ao longo da vida

PREFEITURA DE PORTO ALEGRE. SEJA/MOVA. Palavras de trabalhador. Porto Alegre, 2003.

SAPÉ. Almanaque Aluá n. 2. jan. 2006. Rio de Janeiro: SAPÉ. Disponível em: http://www.dominiopublico.gov.br/download/texto/me003418.pdf. Acesso em 7 jun. 2018. 